- Trong nghiên cứu này các thói quen sử dụng đồ ngọt, hành vi sử dụng thuốc lá, thuốc lào, thói quen tập thể dục ảnh hưởng đến tình trạng dinh dưỡng chưa cho thây sự khác biệt giữa các nhóm.

\section{TÀl LIẸU THAM KHẢO}

1. Audrain-McGovern, J. and Benowitz, N. L. (2011), "Cigarette smoking, nicotine, and body weight", Clinical pharmacology and therapeutics. 90(1), pp. 164-168.

2. Mahfouz, A. A., et al. (2011), "Nutrition, physical activity, and gender risks for adolescent obesity in Southwestern Saudi Arabia", Saudi J Gastroenterol. 17(5), pp. 318-22.

3. Ruano, C., et al. (2011), "Dietary fat intake and quality of life: the SUN project", Nutr J. 10, p. 121.

4. Seo, D. C. and $\mathbf{L i}$, K. (2010), "Leisure-time physical activity dose-response effects on obesity among US adults: results from the 1999-2006
National Health and Nutrition Examination Survey", J Epidemiol Community Health. 64(5), pp. 426-31.

5. Shaista Malik, Nathan D. Wong, and Stanley S. Franklin (2004), "Impact of the Metabolic Syndrome on Mortality From Coronary Heart Disease, Cardiovascular Disease, and All Causes in United States Adults", Circulation. 110, pp. 1245-1250.

6. Wareham, N. J., van Sluijs, E. M., and Ekelund, U. (2005), "Physical activity and obesity prevention: a review of the current evidence", Proc Nutr Soc. 64(2), pp. 229-47.

7. Whitton, C., et al. (2011), "National Diet and Nutrition Survey: UK food consumption and nutrient intakes from the first year of the rolling programme and comparisons with previous surveys", Br J Nutr. 106(12), pp. 1899-914.

8. WHO (2011), Global status report on noncommunicable diseases 2010, WHO press, Geneva, Switzerland.

9. Hà Huy Khôi (2002), Dinh dưỡng dư phòng các bệnh mạn tính, Nhà xuất bản Y học, Hà Nội.

\title{
ĐĂC ĐIỂM LÂM SÀNG KHUYÊT MI DƯỚI VÀ KẾT QUẢ PHẪU THUÂTT TẠO HÌNH KHUYẾT MI DƯớI
}

\section{Lê Trọng Tiến ${ }^{1}$, Tạ Thị Hồng Thúy ${ }^{2}$, Phạm Thị Việt Dung²}

\section{TÓM TẮT}

Bài báo nhằm mô tả đăc điểm lâm sàng và đánh giá kết quả phẫu thuật tạo hình che phủ khuyết tổn mi dưới. Nghiên cứu thực hiện trên 32 bệnh nhân với tổn khuyết mi dưới được phầu thuât tao hình che phủ tai Khoa Phẫu thuật tạo hình - Bệnh viện Đa Khoa Xanh Pôn. Kết quả cho thấy đă̆c điểm tổn khuyết mi dưới do nguyên nhân chấn thương là chính tỉ lệ $56,3 \%$; Khối u và seo co kéo mi dưới chiếm $43,7 \%$. Trong nghiên cứu nhóm không có tổn thương bờ mi là chủ yếu $(81,2 \%)$; vi trí tốn khuyết trên hai vị trí chiếm $(50 \%)$; về độ sâu tổn thương chia làm 2 nhóm: nhóm tôn thương bề măt $(56,2 \%)$ và nhóm tổn thương toàn bô chiêu dày mi $(43,8 \%)$. Phương pháp tạo hình che phủ tổn khuyết: vạt tại chô̂ $(56,2 \%)$; Vạt lân cận $(28 \%)$ ghép da (9,4\%). Kết quả gần sau phẫu thuật 90,6\% chức năng tốt và $68,8 \%$ thẩm mỹ tốt. Kết quả sau 3 tháng chức năng mi dưới đạt 93,8\% tốt và thẩm mỹ mi dưới đat $53,1 \%$ tốt. Như vây, khuyết mi dưới rất đa dạng về tổn thương, có nhiều phương pháp tạo hình che phủ từ đơn giản tới phức tap. Mục tiêu giải quyết chức năng được đặt lên hàng đầu và có kết quả khả quan. Mục tiêu đáp ứng nhu câu về thẩm mỹ vẫn còn là thách thức với các phâu thuật viên tạo hình.

Tư khoá: khuyết mi dưới, vạt tại chố, ghép da

\footnotetext{
${ }^{1}$ Bệnh viện Hữu nghị Đa khoa Nghệ $A$ 2Trường đại hoc Y Hà nội

Chịu trách nhiệm chính: Lê Trọng Tiến

Email: trongtien.dhyduoc@gmail.com

Ngày nhận bài: 12.8.2021

Ngày phản biên khoa hoc: 7.10.2021

Ngày duyệt bài: 18.10.2021
}

\section{SUMMARY \\ THE CLINICAL CHARACTERISTICS AND EVALUATE THE RESULTS OF PLASTIC SURGERY TO COVER LOWER EYELID DEFECTS}

The paper aims to describe the clinical characteristics and evaluate the results of plastic surgery to cover lower eyelid defects. The study was conducted on 32 patients who have lower eyelid defects covered by plastic surgery at the Department of Plastic Surgery - Saint Paul General Hospital. The results showed that the characteristics of lower eyelid defects caused by trauma were the main rate of $56.3 \%$; By tumors and scars that pull on the lower eyelids account for $43.7 \%$. In the study, the group without blepharoplasty accounted for the majority $(81.2 \%)$; group with more than two defects about $50 \%$; In terms of depth of damage, it was divided into 2 groups: superficial lesions $(56.2 \%)$ and full thickness lesions (43.8\%). The method of shaping to cover the defect: flap in place $(56.2 \%)$; adjacent flap $(28 \%)$ skin graft $(9.4 \%)$. Close results after surgery, $90.6 \%$ good function and $68.8 \%$ good aesthetic. After 3 months, the lower eyelid function was achieved $93.8 \%$ good and the lower eyelid aesthetic was achieved $53.1 \%$ good. Thus, lower eyelid defects are very diverse in terms of damage, there are many methods of covering from simple to complex. The goal of solving the function is put on the top and there are positive results. The goal of meeting aesthetic needs is still a challenge for plastic surgeons.

Keywords; lower eyelid defect, in situ flap, skin grafting.

\section{I. ĐặT VẤN ĐỀ}


Khuyết phần mềm mi mắt mi dưới rất đa dạng, từ đơn giản đến phức tạp và là tổn thương khó tạo hình. Nguyên nhân của các tổn khuyết này có thể do phẫu thuật, chấn thương, cắt bỏ khối u hay do bẩm sinh v.v... Nếu không được điều trị đúng phương pháp có thể gây tổn hại chức năng mi, trực tiếp ảnh hưởng đến nhãn cầu, chức năng thị giác và mất tính thẩm mỹ. Từ thập niên 60, phẫu thuật mi mắt được chú trọng hơn, nhiều phương pháp, kỹ thuật tạo hình được ứng dụng hơn, được thể hiện qua báo cáo của nhiêutác giả: Callahan (1966) ${ }^{1}$, Hughes W.L $(1973)^{2}$, Mustarde J.C (1979)3 với các kỹ thuật vạt tại chỗ, lân cận và từ xa... Từ đó đển nay, trên cơ sở nền tảng là những dạng vạt cơ bản đó, nhiều tác có một số cải tiến hoặc đưa ra các kỹ thuật mới nhằm mang lại hiệu quả điều trị tốt hơn ${ }^{4}$. Ở Việt Nam, cũng đã có một số nghiên cứu về tổn thương khuyết mi: nghiển cứu phẫu thuật điều trị tổn thương khuyết mi của Phạm Trọng Văn, nghiên cứu tạo hình khuyết mi của Lê Minh Thông, nghiên cứu tạo hình khuyết mi bẩm sinh ở trẻ em của Lê Đố Thùy Lan, nghiên cứu tao hình khuyết mi dưới bằng vat nhánh trán động mạch thái dương nông của Phạm Thị Việt Dung... Để góp thêm kinh nghiệm về điều trị khuyết phần mềm mi dưới, tác giả viết bài này với với mục tiêu là mô tả đắc điểm lâm sàng khuyết mi dưới và đánh giá kết quả phẫu thuật tạo hình khuyết mi dưới.

\section{II. ĐỐI TƯỢNG VÀ PHƯƠNG PHÁP NGHIÊN CỨU}

Nghiên cứu mô tả cắt ngang trên 32 bệnh nhân vớikhuyết phần mềm mi dưới được phẫu thuật tại Khoa Phẫu thuật tạo hình- Bệnh viện Xanh Pồn từ tháng 08 nằm 2015 đến tháng 06 năm 2021.

Bảng 1. Đánh giá kêt quả lâm sàng sau 3tháng.

\begin{tabular}{|c|c|c|c|}
\hline Đặc điếm lâm sàng & Tốt & Khá & Kém \\
\hline Sẹo & $\begin{array}{c}\text { Mảnh } \leq 2 \mathrm{~mm} \text {, } \\
\text { nhìn trực diện mới thấy }\end{array}$ & $\begin{array}{c}\text { Giãn>2mm, nhìn rõ ở cự } \\
\text { ly } 1 \mathrm{~m}\end{array}$ & $\begin{array}{l}\text { Lồi, phì đại, nhìn rõ ở } \\
\text { cự ly > } 1 \mathrm{~m}\end{array}$ \\
\hline Màu sắc & $\begin{array}{l}\text { Tiệp màu với da xung } \\
\text { quanh }\end{array}$ & Hơi khác biệt & Khác biệt hoàn toàn \\
\hline Trê mi & Không trề mi & $\leq 2 \mathrm{~mm}$ & $>2 \mathrm{~mm}$ \\
\hline Hở mi & Không hở mi & $\leq 2 \mathrm{~mm}$ & $>2 \mathrm{~mm}$ \\
\hline Chức năng & $\begin{array}{c}\text { Nhắm mở thoải mái, } \\
\text { không hở mi, chảy } \\
\text { nước mắt }\end{array}$ & $\begin{array}{c}\text { Cảm giác không thoải } \\
\text { mái khi nhắm mở mắt, } \\
\text { Hở mi vẫn che được } \\
\text { giác mac }\end{array}$ & $\begin{array}{c}\text { Nhắm mở mắt hạn } \\
\text { chế, Hở mi không che } \\
\text { được giác mạc, chảy } \\
\text { nước măt. }\end{array}$ \\
\hline Thẩm mỹ & $\begin{array}{l}\text { Sẹo mờ, mảnh, da tiệp } \\
\text { màu với vùng xung } \\
\text { quanh, viền mi liên } \\
\text { tuc, không trễ mi }\end{array}$ & $\begin{array}{l}\text { Sẹo giãn, thấy rõ ở cự ly } \\
\text { gần dưới } 1 \mathrm{~m} \text {, màu sắc } \\
\text { hơi khác biết, trễ̂ mi } \\
\text { mức đô vữa (dưới } 2 \mathrm{~mm} \text { ) }\end{array}$ & $\begin{array}{c}\text { Seoo lồi nhìn thấy rõ, } \\
\text { mất liên tục viền mi, } \\
\text { trễ mi nhiêu (trên } \\
2 \mathrm{~mm} \text { ) }\end{array}$ \\
\hline
\end{tabular}

Tất cả các bệnh nhân được khám, đánh giá tổn thương phần mềm mi dưới về nguyên nhân, kích thước, độ sâu và những tổn thương phối hợp hoặc ảnh hưởng tới chức năng mắt rồi xác định phương pháp tạo hình dựa trên đặc điểm tổn thương.

Dưới gây mê nội khí quản hoặc tê tại chỗ tuỳ theo mức độ nặng của tổn khuyểt, mi dưới được cắt lọc làm sạch trong chấn thương hoặc cắt bỏ tổn thương với những trường hợp u và sẹ. Đánh giá đặc điểm tổn thương và các tổn thương kèm theo nếu có như hốc mắt, nhãn cầu, sọ mặt, cơ quan phối hợp..., tiếp đó, dựa vào tổn thương và tình trạng từng bệnh nhân để chọn phương pháp phấu thuật tạo hình là khâu trực tiếp, ghép da sau tai, vạt tại chố hay vạt lân cận.

\section{Kết quả sau mố:}

*Đánh giá khi bệnh nhân ra viện dựa trên các tiêu chí: Tình trạng liền thương, chảy máu, nhiễm trùng, sức sống của vạt hoặc da ghép và chức năng của mi dưới để chia thành 3 mức độ:

+ Tốt: Vạt hoặc da ghép sống tốt, không chảy máu, không nhiễm trùng, vết mổ liền tốt,không trễ mi, nhắm mắt kín.

+ Khá: Vat hoặc da ghép sống toàn bộ nhưng chậm liển ở nơi cho hoặc nhận vạt, hoặc bị các biến chứng như ứ tĩnh mạch, thiểu dưỡng, hoại tử một phần vạt hoặc chảy máu nhiễm trùng tại chố, chậm liền...nhưng tiên lượng không để lại di chứng, trễ mi dưới, mắt nhắm không kín nhưung vẫn che được giác mạc.

+ Kém: Vạt hoặc da ghép hoại tử phần lớn hoăc toàn bộ, trễ mi, nhắm mắt không kín, phải phẫu thuật lại.

*Đánh giá sau 3 tháng dựa vào các tiêu chí theo bảng sau: 


\section{KẾT QUẢ NGHIÊN CỨU}

*Đặc điểm lâm sàng: Trong 32 bênh nhân khuyết mi dưới độ tuổi hay gặp nhất là độ tuổi lao động từ 16 đến 60 tuổi chiếm $68,7 \%$, trẻ em ít gặp chiếm 18,8\% phần lớn là tổn khuyết sau cắt bỏ nơvi hắc tố bẩm sinh vùng $\mathrm{mi}$ dưới. Nguyên nhân chủ yếu là chấn thương $18 / 32$ bệnh nhân $(56,3 \%)$ do tai nạn giao thông, sinh hoạt và lao động. Phẫu thuật cắt các khối u vùng mi dưới 10/32 bệnh nhân (31,3\%) như nơvi hắc tố bẩm sinh, u máu, u vàng; sẹo do di chứng bỏng, co kéo mi dưới, trễ mi sau phẫu thuật thẩm mỹ $4 / 32$ bệnh nhân (12,5\%). Trong số 32 bệnh nhân khuyết mi thì có 6 trường hợp tổn thương bờ mi hoàn toàn $(18,8 \%)$ do chấn thương. 13/32 bệnh nhân tồn khuyết toàn bộ chiều dày mi trên (40,6\%). Kích thước tổn thương $>1 / 2$ chiều dài mi với $7 / 13$ bệnh nhân $(53,8 \%)$. Đây là các tổn khuyết rất khó tạo hình. Các khuyết còn lại đơn giản hơn, chiếm $<1 / 2$ chiều dài mi dưới và chỉ khuyết lớp da, cơ của mi dưới.

*Phương pháp phấu thuật:

Bảng 2. Phương pháp điều trị với kích thước khuyêt mi dưới

\begin{tabular}{|c|c|c|c|c|c|c|c|}
\hline $\begin{array}{l}\text { Phương Phá } \\
\text { Kích thước }\end{array}$ & $\begin{array}{l}\text { Khâu trực } \\
\text { tiếp }\end{array}$ & Ghép da & Vạt tại chổ & \multicolumn{2}{|c|}{ Vạt lân cận } & \multicolumn{2}{|c|}{ Tổng } \\
\hline$<1 / 4$ chiều dài & $1(33,3 \%)$ & $0(0 \%)$ & $2(66,7 \%)$ & \multicolumn{2}{|c|}{$0(0 \%)$} & \multicolumn{2}{|c|}{$3(100 \%)$} \\
\hline $1 / 4-1 / 2$ chiều dài & $1(7,1 \%)$ & $0(0 \%)$ & $11(78,5 \%)$ & \multicolumn{2}{|c|}{$2(14,2 \%)$} & \multicolumn{2}{|c|}{$14(100 \%)$} \\
\hline$>1 / 2$ chiều dài & & $3(20 \%)$ & & \multicolumn{2}{|c|}{$7(46,7 \%)$} & \multicolumn{2}{|c|}{$15(100 \%)$} \\
\hline Tống & $2(6,2 \%)$ & $3(9,4 \%)$ & $18(56,2 \%)$ & \multicolumn{2}{|c|}{$9(28,1 \%)$} & \multicolumn{2}{|c|}{$32(100 \%)$} \\
\hline \multirow{4}{*}{\multicolumn{3}{|c|}{$\begin{array}{l}\text { Nhóm } 15 \text { bệnh nhân khuyết mi dưới có kích } \\
\text { thước tổn khuyết }>1 / 2 \text { chiều dài mi thì phương } \\
\text { pháp phẫu thuật tạo hình hay sử dưng nhiều } \\
\text { nhất là vạt lân cận là } 7 / 15 \text { bệnh nhân }(46,7 \%) \\
\text { trong đó Vạt Mustarde là } 6 / 15 \text { bệnh nhân }\end{array}$}} & \multicolumn{5}{|c|}{$\begin{array}{l}\text { *Kết quả phấu thuật } \\
\text { Bảng 3: Kết quả khi bênh nhân ra viên: }\end{array}$} \\
\hline & & & \multicolumn{2}{|c|}{ Đặc điểm lâm sàng } & Tốt & Khá & Kém \\
\hline & & & \multicolumn{2}{|c|}{ Số ca } & 25 & 7 & 0 \\
\hline & & & \multicolumn{2}{|l|}{ Tỷ lệ } & $78,1 \%$ & $21,9 \%$ & $0 \%$ \\
\hline
\end{tabular}
(40\%)và vạt rãnh mũi má với $1 / 15$ bệnh nhân (6,6\%) nhóm bệnh nhân này, phương pháp khâu trực tiếp không được áp dụng trường hợp nào. Nhóm 14 bệnh nhân khuyết mi dưới có kích thước tổn khuyết 1/4 -1/2chiều dài mi thì phương pháp phẫu thuật tạo hình được sử dụng nhiêu nhất là vạt tại chổ với $11 / 14$ bệnh nhân (78,5\%) với $6 / 14$ bệnh nhân $(42,8 \%)$ là vạt dồn đẩy và $5 / 14$ bệnh nhân $(35,7 \%)$ là vạt chuyển, vạt xoay.

Trong 32 trường hợp sau mố, có 25 bênh nhân tốt, 7 bệnh nhân khá và 0 bệnh nhân có kết quả kém. Qúa trình sau mổ xảy ra một số biến chứng ở một số bệnh nhân như có 4 bệnh nhân nhiễm trùng vết mổ, chậm liền thương, có 3 bênh nhân vạt bị ứ tĩnh mạch nhưng sau đó diễn biến theo trình tự: 3 ngày đầu vạt tím, ứ máu đen, sang ngày thứ 4, 5 vạt bắt đầu sáng dần lên và màu sắc hoàn toàn bình thường sau 7- 10 ngày.

Bảng 4. Kêt quả các đặc điểm lâm sàng sau 3 tháng

\begin{tabular}{|c|c|c|c|c|}
\hline Đặc điếm lâm sàng & Tốt & Khá & Kém & Tống \\
\hline Sếo & $22(68,8 \%)$ & $10(31,2 \%)$ & $0(0 \%)$ & $32(100 \%)$ \\
\hline Trể mi & $30(93,8 \%)$ & $2(6,2 \%)$ & $0(0 \%)$ & $32(100 \%)$ \\
\hline Hở mi & $31(96,9 \%)$ & $1(3,1 \%)$ & $0(0 \%)$ & $32(100 \%)$ \\
\hline Màu sắc & $22(68,8 \%)$ & $10(31,2 \%)$ & $0(0 \%)$ & $32(100 \%)$ \\
\hline Chức năng & $31(96,9 \%)$ & $1(3,1 \%)$ & $0(0 \%)$ & $32(100 \%)$ \\
\hline Thấm mỹ & $31(96,9 \%)$ & $1(3,1 \%)$ & $0(0 \%)$ & $32(100 \%)$ \\
\hline
\end{tabular}

Đa số bênh nhân phẫu thuât tao hình khuyết mi dưới cho kết quả thẩm mỹ tốt và khá theo thời gian 3 tháng. Tuy nhiên sau thời gian 3 tháng bệnh nhân kết quả tốt có giảm xuống do biến chứng trễ mi nặng, sẹo xấu hơn và phục hồi thẩm mỹ chưa đạt yêu cầu.

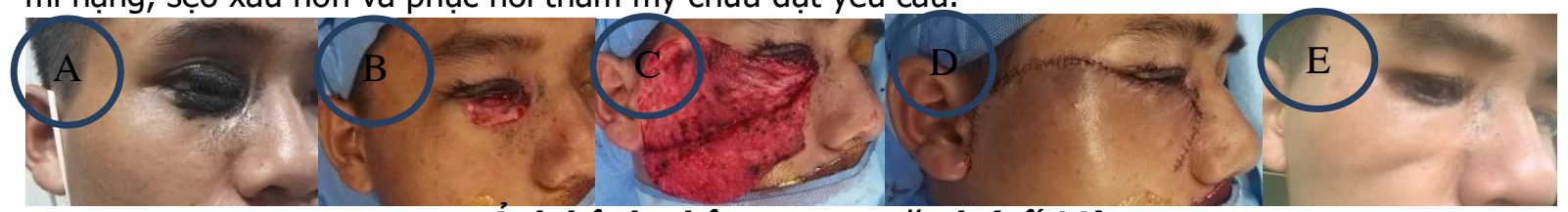

Ánh bệnh nhân trương văn l. (số 11)

(A: u hắc tố mi trên mi dưới, B: bóc ư để lại tổn khuyết, C: kiểm tra cầm máu diện bóc tách, D: khâu phục hồi lại tổn khuyết, $E$ : hình ảnh bệnh nhân sau mổ 3 tháng) 


\section{BÀN LUÂN}

Trong nhóm nghiên cứu có 3 nhóm nguyên nhân gây khuyết, chủ yếu là chấn thương chiếm $56,3 \%$; khuyết thứ phát sau phẫu thuật cắt các khối u vùng mi dưới chiếm $31,3 \%$ như nơvi hắc tố bẩm sinh, u máu, u mõ vàng; tổn khuyết do di chứng sẹo bỏng, sẹo co kéo mi dưới, trế mi sau phẫu thuật thẩm mỹchiếm 12,5\%. Với 3 nhóm nguyên nhân gây khuyết, số lượng bệnh nhân bị chấn thương chiếm tỷ lệ cao phần lớn do tai nạn giao thông tương ứng với thực trạng tai nạn giao thông ở Việt nam. Khác với các nước phát triển, ti lệ khuyết mi dưới do chấn thương rất thấp, chủ yếu là khuyết sau phẫu thuật lấy bỏ khối u.

Theo Ali Tabatabaei $(2013)^{\mathbf{6}}$ tỳ lệ khuyết mi có tổn thương bờ mi chiếm $5,2 \%$; tỷ lệ không tổn thương bờ mi chiếm 94,8\%. Trong nhóm nghiên cứu của chúng tôi gồm 32 bệnh nhân thì nhóm có tổn thương bờ mi chiếm $6 / 32$ bệnh nhân $(18,8 \%)$ và số bệnh nhân này đều do nguyên nhân chấn thương. Còn với các nguyên nhân khác như phẫu thuật lấy bỏ u hay sửa sẹo co kéo do bỏng hay phấu thuật thẩm mỹ thì tính chất tổn khuyết và sự chủ động của phẫu thuật viên sẽ không ảnh hưởng đến bờ mi nếu không cần thiết. Trong nhóm nghiên cứu có 19 bệnh nhân tổn thương lớp da cơ chiếm 59,4\%, trong đó có $1 \mathrm{ca}$ tổn thương $<1 / 4$ chiều dài $\mathrm{mi}, 9 \mathrm{ca}$ tổn thương kích thước $1 / 4-1 / 2$ chiều dài mi và 8 ca> $1 / 2$ chiều dài mi. 13 bệnh nhân còn lại tổn thương mất toàn bộ chiều dày mi chiếm $40.6 \%$ tổng số nghiên cứu trong đó có 2 ca tổn thương $<1 / 4$ chiêuu dài mi, 4 ca tổn thương kích thước $1 / 4-1 / 2$ chiều dài mi và 8 case $>1 / 2$ chiều $\mathrm{mi}$. Đặc điểm tổn thương này thấy rằng tương ứng với loại gây ra tổn thương củaAli Tabatabaei (2013) và tác giả Herzum (2001) ${ }^{7}$.

Nghiên cứu có 13 bệnh nhân khuyết toàn bộ chiêu dày mi chiếm tỷ lệ $40,6 \%$. Trong đó, $7 / 13$ vạt lân cận $(53,7 \%)$ gồm6/7 trường hợp vạt Mustarde và $1 / 7$ vạt rãnh mũi má, điêu này cũng hợp lý với tổn thương lớn, độ sâu tổn khuyết nhiều, mất tổ chức hoàn toàn chiều dày mi thì việc sử dụng vạt để che phủ tổn khuyết là phù hợp với độ dày, màu sắc da và tổ chức mi dưới. Trong nhóm bệnh nhân khuyết toàn bộ chiều dày mi thì có duy nhất 1 case được sử dụng phương pháp phẫu thuật tạo hình là khâu trực tiếp vớitổn thương sâu mất toàn bộ chiều dày nhưng mà kích thước nhỏ hơn $<1 / 4$ chiều dài micho kết quả phục hồi khá tốt. Với nhóm khuyết phần mềm mi dưới tổn thương lớp da cơ có 19 case chiếm tỷ lệ 59,4\% thì phương pháp phẫu thuật tạo hình cả 4 phương pháp đều được sử dụng, trong đó, vạt tại chổ được sử dụng nhiêu nhất với $69,3 \%$ và sử dụng thêm vạt lân cận, phương pháp ghép da và phương pháp khâu trực tiếp. Như vâyy trong nhóm nghiên cứu của chúng tôi có sử dụng $6,2 \%$ khâu trực tiếp; 9,4\% ghép da; $56,2 \%$ vạt tại chổ (trong đó $31,2 \%$ vạt dồn đấy, $25 \%$ vạt xoay chuyển) và $28,1 \%$ vạt lân cận (trong đó $21,8 \%$ vạt Mustarde, $6,3 \%$ vạt rãnh mũi má). Theo tác giả Fang $S(2016)^{4}$ nghiên cứu trên bệnh nhân khuyết hổng mi dưới kích thước lớn, sâu mất toàn bộ chiều dày mi dưới đã được tác giả sử dụng phương pháp phẫu thuật tạo hình làm vạt lân cận đạt kết quả tốt. Theo tác giả $F$. Moschella, A. Cordova and C. Di Gregorio ${ }^{8}$ nghiên cứu sử dụng vạt lân cận và vạt tại chổ để phục hồi lại tổn khuyết mất toàn bộ chiêu dày mi dưới.

Đánh giá kết quả ra viên đa số bệnh nhân có kết quả tốt, chỉ có một số bệnh nhẩn xuất hiện biến chứng, đặc biệt là hiện tượng vạt ứ tĩnh mạch sau mổ, 3 ngày đầu vạt ứ máu đen, tím đển 4,5 ngày sau vạt bắt đầu sáng màu lên và sau 7-10 ngày vạt hoàn toàn bình thường và không để lại di chứng. Hiện tượng này cũng thường gặp ở nghiên cứu của các tác giả khác. Năm 2015, Jun Yong Leebáo cáo nghiên cứu 17 bênh nhân khuyết phần mềm vùng măt vừa và nhỏ sử dụng các vạt nhánh xuyên kiểu tự do "free style", dựa trên các nhánh động mạch thái dương, động mạch chẩm, động mạch sau tai, động mạch mặt... kết quả có 3 vạt bị hoại tứ, trong đó có 1 vạt hoại tử toàn bộ do ứ tĩnh mạch. Năm 2002, Ozdemir R cũng báo cáo 28 trường hợp phẫu thuật tạo hình vùng mặt sử dụng vạt lân cận thì có đến 6 trường hợp bị ứ tĩnh mạch, tuy nhiên cũng không có trường hợp nào hoại tử.

Theo dõi kết quả sau phẫu thuật 3 tháng, xét thấy kết quả lâm sàng ở các nhóm nguyên nhân khác nhau, sử dụng phương pháp tạo hình khác nhau sẽ cho kết quả khác nhau. Trên nhóm nguyên nhân có kích thước nhỏ, tổn thương nông, sử dụng phương pháp khâu trực tiếp sẽ cho kết quả tốt về cả chức năng và hình thể, màu sắc mi dưới. Ở nhóm sử dụng phương pháp ghép da, mặc dù nhóm nghiên cứu chỉ sứ dụng vat da sau tai, có màu sắc tương đồng, tuy nhiên khi ghép lên thì kết quả vẫn không giống hoàn toàn với da lân cận, màu sắc khác và mất thẩm mỹ.

\section{KẾT LUÂN}

Tổn thương khuyết mi dưới là một tổn thương đa dạng với nguyên nhân hay gặp nhất là chấn thương. Kết quả tạo hình che phủ khuyết mi 
dưới sử dụng các phương pháp như khâu đóng trực tiếp, ghép da hay tới sử dụng vạt tại chỗ, vạt lân cận mang lại hiệu tốt về cả chức nằng và thẩm mỹ mi mắt. Mỗi phươngpháp đều có ưu nhược điểm, tuy nhiên vừa đảm bảo chức năng và tính thẩm mỹ không phải là sự dễ dàng.

\section{TÀI LIÊU THAM KHẢO}

1. Callahan C. "Entropion", reconstructive surgery of the eyelids and ocular adnexa,.In:; 1966:120-130.

2. Hughes W.L. "A new method of rebuilding a lower - lid", Arch. Ophth.17. In: ; 1973:10081017.

3. Mustarde J.C. "Reconstruction of the eyelid and eyebrows and correction of ptosis of the eyelid", Plastic Surgery. In: ; 1979:280-298.

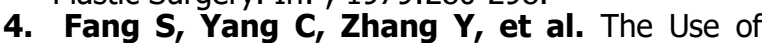

Composite Flaps in the Management of Large FullThickness Defects of the Lower Eyelid. Medicine (Baltimore). 2016;95(2). doi:10.1097/ MD.0000000000002505.

5. Pham Thi Việt Dung. Nghiên cứu tao hình khuyết mi dưới bằng vạt nhánh trán động mạch thái dương nông.

6. Tabatabaei A, Kasaei A, Nikdel M, et al. Clinical Characteristics and Causality of Eye Lid Laceration in Iran. Oman Med J.2013;28(2): 97-101. doi: 10.5001/omj.2013.26.

7. Herzum $H$, Holle $P$, Hintschich C. (2001) "Lidverletzungen: epidemiologische Aspekte", Augenheilkunde, Augenklinik, Universitat Muchen, 98 (11). In: ; :1079-1082.

8. F. Moschella, A. Cordova and C. Di Gregorio. Lower eyelid reconstruction by multiple subcurtaneous pedicle flaps: a new method.

\section{TÁC DUUNG GIẢM ĐAU VÀ CẢI THIÊN TẦM VÂN Đô̂NG CộT SỐNG Cổ CỦA PHÚC CHÂM TRONG ĐIỀU TRI HộI CHỨNG CỔ VAI CÁNH TAY DO THOÁI HÓA CộT SỐNG Cổ}

\section{TÓM TẮT}

Muc tiêu: Đánh giá tác dụng giảm đau và cải thiện tầm vận động cột sống cồ của phúc châm trong điều trị hội chứng cố vai cánh tay do thoái hóa cột sống cổ. Phương pháp: Nghiên cứu lâm sàng mớ, tiến cứu, so sánh trước và sau điều trị có đối chứng. 60 bệnh nhân chia thành 2 nhóm: nhóm nghiên cứu dùng phúc châm kết hợp xoa bóp bấm huyệt, nhóm chứng dùng điện châm kết hợp xoa bóp bấm huyệt. Kết quả: Sau 21 ngày điều trị, ở nhóm nghiên cứu, điểm VAS trung bình giảm từ $5,43 \pm 1,17$ xuống 2,70 $\pm 1,39$ điểm $(p<0,05)$; cải thiện rõ rệt tầm vận đông côt sống cổ $(\mathrm{p}<0,05)$ và khổng có sứ khác biệt với nhóm chứng ( $p>0,05)$. Kết luận: Phúc châm có tác dung giảm đau và cải thiện tầm vân đông cột sống cổ trong điều trị hội chứng cổ vai cánh tay do thoái hóa côt sống cổ.

Tư khoá: Phúc châm, hội chứng cổ vai cánh tay, thoái hoá cột sống cổ.

\section{SUMMARY \\ EFFECTS OF ABDOMINAL ACUPUNCTURE ON RELIEVING PAIN AND IMPROVING CERVICAL}

\footnotetext{
${ }^{1}$ Trường Đại học Y dược Thái Bình

${ }^{2}$ Bệnh viện Y học cổ truyền Trung ương

${ }^{3}$ Trường Đại học Y Hà Nội

Chịu trách nhiệm chính: Dương Trọng Nghĩa

Email: dtnghia72@yahoo.com

Ngày nhận bài: 10.8.2021

Ngày phản biên khoa họ: 8.10.2021

Ngày duyệt bài: 18.10.2021
}

\author{
Lưu Thị Trang Ngân', Đỗ Quốc Hương', \\ Dương Trọng Nghĩa ${ }^{2}$, Nguyễn Kim Ngọc
}

\section{SPINE MOTION RANGE IN TREATMENT CERVICAL SCAPULOHUMERAL SYNDROM DUE TO CERVICAL SPONDYLOSIS}

Objectives: Evaluate the analgesic effect and the ability to improve cervical spine movement of abdominal - acupuncture in treatment cervical scapulohumeral syndrom due to cervical spondylosis. Methods: this is an open - clinical trial with comparison before and after treatment's result and compare with control group. 60 patients were divided into two group: the study group used abdominal acupuncture combined with massage - acupuncture, the control group used electro - acupuncture combined with massage - acupuncture. Results: after 21 days of treatment, in the study group, the mean VAS score decreased from $5.43 \pm 1.17$ (points) to $2.70 \pm 1.39$ (points) $(p<0.05)$; improved the range of cervical spine motion $(p<0,05)$. There were no statistically significant difference between the two group ( $p>0.05)$. Conclusion: Abdominal acupuncture has good effects on pain relief and improving movement of cervical spine in treatment cervical scapulohumeral syndrom due to cervical spondylosis.

Keywords: Abdominal - acupuncture, cervica scapulohumeral syndrom, cervical spondylosis.

\section{I. ĐẶT VẤN ĐỀ}

Hội chứng $(\mathrm{HC})$ cổ vai cánh tay là môt $\mathrm{HC}$ bệnh phổ biến với biểu hiện lâm sàng là đau và rối loạn cảm giác, vận động vùng cổ vai cánh tay tương ứng với rễ dây thần kinh bị ảnh hưởng [5]. Nghiên cứu tại khoa Nội thần kinh bệnh viện 103 